\title{
High-Speed Laser Direct Deposition Technology: Theoretical Aspects, Experimental Researches, Analysis of Structure, and Properties of Metallic Products
}

\author{
K.D. Babkin, V.V. Cheverikin, O.G. Klimova-Korsmik, M.O. Sklyar, \\ S.L. Stankevich, G.A. Turichin, A.Ya. Travyanov, E.A. Valdaytseva \\ and E.V. Zemlyakov
}

\begin{abstract}
Additive technologies as an alternative to traditional methods arouse great interest in many industrial sectors. In recent years, many theoretical and experimental articles devoted to additive technologies and their applications have been published. In spite of it, now the area of outstanding issues is still remaining. The paper presents results of theoretical and experimental researches devoted to the stability of products formation from different metallic alloys with complex
\end{abstract}

\footnotetext{
K.D. Babkin · O.G. Klimova-Korsmik · M.O. Sklyar ( $₫)$ · S.L. Stankevich · G.A. Turichin • E.A. Valdaytseva $\cdot$ E.V. Zemlyakov Institute of Laser and Welding Technologies, Peter the Great St. Petersburg Polytechnic University, Saint Petersburg, Russia e-mail: skmar.spb@gmail.com

K.D. Babkin

e-mail: babkin.kd@mail.ru

O.G. Klimova-Korsmik

e-mail: o.klimova@1tc.ru

S.L. Stankevich

e-mail: ssl.07@mail.ru

G.A. Turichin

e-mail: gleb@ltc.ru

E.A. Valdaytseva

e-mail: Ekaterina@ltc.ru

E.V. Zemlyakov

e-mail: e.zemlyakov@ltc.ru
}

V.V. Cheverikin · A.Ya. Travyanov

National University of Science \& Technology (MISiS), Moscow, Russia

e-mail: cheverikin80@ rambler.ru

A.Ya. Travyanov

e-mail: travyanov@mtr.misis.ru 
geometry form, which were manufactured using high-speed direct laser deposition technology. The prospect of application of the method for the manufacturing of various materials details and products for various areas of engineering has been shown.

Keywords Additive manufacturing - High-speed direct laser deposition Surface stable formation - Mechanical properties - Metal powder Nickel-based alloys $\cdot$ Ultrafine structure

New manufacturing technologies are actively incorporated into most areas of engineering: aircraft industry, shipbuilding, medicine, engine construction, etc. The additive technologies have most popularity and become the foundation of a new industry, bringing together digital production, design and through manufacturing cycle. Methods of selective laser melting (SLM) are already integrated in the production both in Russia and in other countries $[9$, p. $290 ; 2$, p. 36; 3, p. 42; 5, p. 98].

The most promising technology for industry of large-sized products from metal powder is high-speed direct metal (or laser) deposition (HSDMD, HSDLD, DMD, DLD). This technology is based on forming product geometry by $3 \mathrm{D}$ cladding of metal powder with laser beam as a heating source [12, p. 177; 10, p. 173]. DMD technology has high productivity and allows building parts for the few minutes, the common growing period for SLM technology is few hours [8, p. 410]. The additive technology of high-speed direct laser deposition application is perspective for the industry because production operations coordinate in uniform parallel process [1, p. 177].

The authors carried out comprehensive theoretical studies on high-speed direct laser deposition process, developed the technology of this process, and produced a working prototype of the equipment. With using these equipment is produced parts from different metal powders, which were investigation to microstructure and mechanical properties.

\section{Theoretical Research}

One of the main features of HSDLD technology is high productivity, which can attain $15 \mathrm{~kg}$ of metallic powder per hour: During growing process motion of the head, relatively product occurs with a high speed. Increase of cladding head motion speed with respect to the product leads to the development of active zone surface instabilities, causing the appearance of defects in the formation of productsquasi-periodic relief on the surface and interrupt the growth process. In the paper $[11$, p. 676], the stability of the process technology is described in details. The condition of process stability is as follows: 


$$
2 \frac{\sigma H^{2}}{v_{0} b^{3} L}<\frac{\partial j}{\partial z}
$$

where $\sigma$ - the surface tension; $\mathrm{H}$ - depth of molten pool; $\mathrm{v}_{0}$-linear velocity of the laser beam over the surface grown item; $b$ - half the width molten pool; $\partial \mathrm{j} / \partial \mathrm{z}$ - the gradient of mass flux density in the gas powder jet at the normal to the surface of the grown product. Figure 1 shows the stabilization process to the surface.

It should be noted that the depth of molten bath in cases 1-3 is related as follows:

$$
H_{1}>H_{2}>H_{3}
$$

Position 2 is level of stable formation of a surface, 1 and 3 of the acceptable process variations, respectively. When there is a change of the depth of molten pool (H) to $\mathrm{H}_{1}$ level length $\mathrm{L}$ and width $\mathrm{b}$ increase. The same situation occurs, when there is a decrease of the depth the molten pool $(\mathrm{H})$ to the $\mathrm{H}_{3}$ level - the length $\mathrm{L}$ and width $b$ decrease. For stabilization of surface position, there are necessary flux density decreases at the displacement to position 1, as a result, the thickness of the deposited layer decreases. When the depth of molten pool change to $\mathrm{H}_{3}$ level thickness of the deposited layer increase, at the constant value of flux density for every 1-3 cases. Thus, the particle flux density determines the stability of the process, and for the fulfillment of this condition is to have the focus of gas powder jet below the working area of deposition.

High-speed growth process also leads to the presence of partially molten particles in the microstructure of deposited samples (Fig. 2a). In the work [4, p. 462; 7, p. 718], the heterophase process is shown on nickel-based alloy (Inconel 625). Figure $2 \mathrm{~b}$ shows how it looks during the deposition process.

Heating gas powder jet laser affects the appearance of heterophase structures in the metal deposited products. Unmelted nuclei of particles is dropping in melt pool and save initial structure in structure of deposited part. In melt pool act hydrodynamic processes because of them unmelted powder particle move to the edge melt

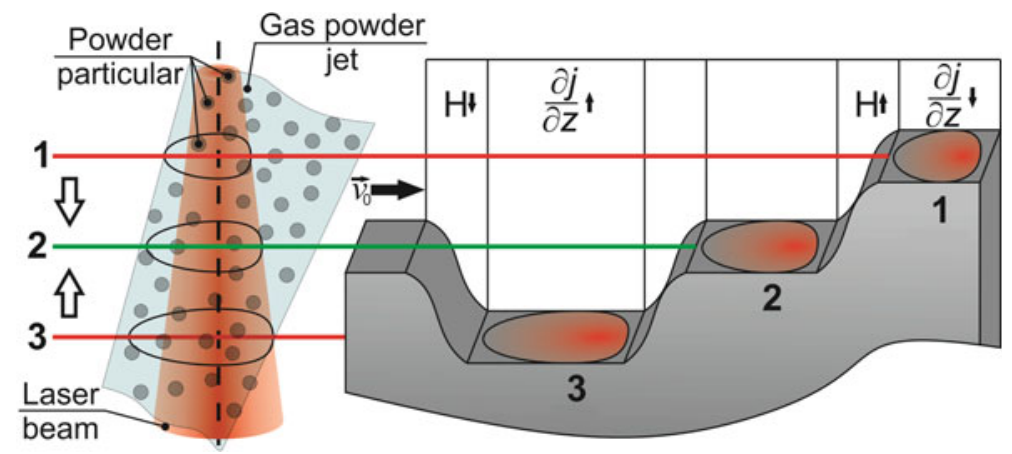

Fig. 1 Scheme of stabilization process 
(a)

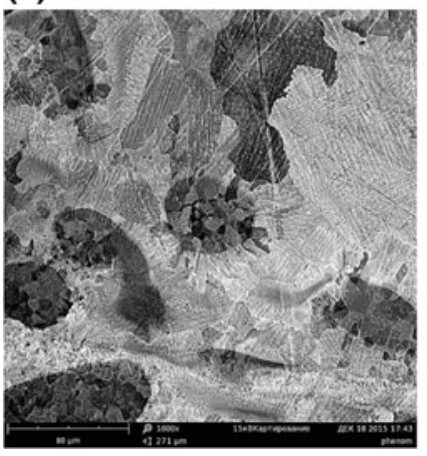

(b)

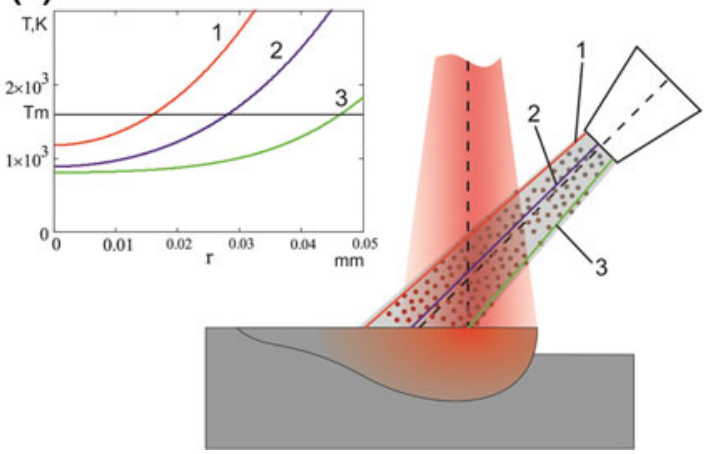

Fig. 2 Microstructure of deposited sample (a) result of simulation of heterophase process (b)

pool where crystallization occurs. Based on the simulation results, it was found that temperature field (Fig. 2b) of powder and particle radius of unmelted particles depends directly on the residence time of the particles in the laser radiation zone. Exposure time depends on the speed of the gas powder jet and powder particles trajectories of movement. The presence of heterophase process by HSDLD process allows to get the fine structure of metal products.

\section{Materials and Methods}

Theoretical and experimental studies of deposition processes were carried out at the Institute of Laser and Welding Technologies SPbPU (ILWT) using experimental setup (Fig. 3). The equipment consists of $5 \mathrm{~kW} \mathrm{Yb}$ fiber laser LS-5 with external focusing optics, made on the base of IPG welding head, a powder disc feeder Medicoat AG with a COAX-11 jet, and a two-dimensional moving stage equipped with a revolving motor. Gas powder jets were formed by lateral and coaxial nozzles, designed with consideration of deposition stability condition. For deposition tool motion, a high precision 6 axis FANUC robot has been used.

Fractional composition of the powders used was varied in the range of 50-150 microns, the shape of the particles - spherical. The deviation from sphericity did not exceed 5\%. Experimental studies were conducted on nickel-based alloys (Inconel 625, Inconel 718, GS6U, EI698P etc.), titanium (Grade 2, Grade 5, VT20, etc.), and steel (316L).

Metallographic studies were carried out on microscope DMI 5000 (Leica) with software Tixomet. Researches of chemical compound and the distribution of chemical elements are made on scanning electron microscope Phenom ProX and Mira Tescan microscope using console Oxford INCA Wave 500. To determine the mechanical properties, samples were tested on uniaxial tension, using universal testing machine Zwick/Roell Z250 Allround. 


\section{(a)}

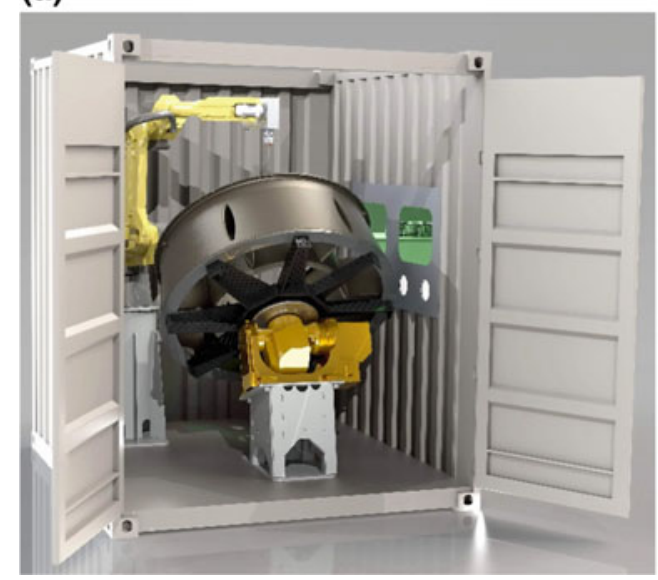

(b)

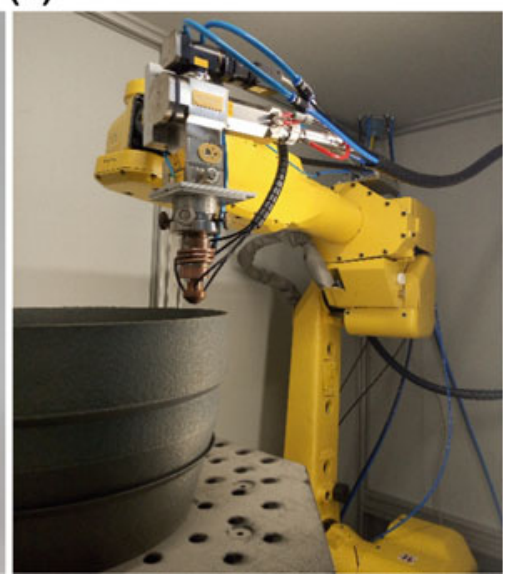

Fig. 3 Experimental setup: a scheme, b photo

\section{Experimental Results}

As a result of the work using the lateral and coaxial nozzles products with different geometry and from the different powder alloys were manufactured. Using different gas powder nozzles, high process productivity was achieved. Lateral feed with scanning has productivity of manufacturing part blanks above $18 \mathrm{~kg} / \mathrm{h}$ (thin wall $3-20 \mathrm{~mm}$ ); lateral feed by focused gas powder jet has productivity above $5 \mathrm{~kg} / \mathrm{h}$ (wall $0.8-3 \mathrm{~mm}$ ); coaxial feed by focused jet — productivity above $1 \mathrm{~kg} / \mathrm{h}$ (wall $0.6-2 \mathrm{~mm}$ ) (Fig. 4).

Process parameters were chosen for each group of alloys (iron-based, titanium-based, nickel-based, including a high-bar gamma phase). Samples of
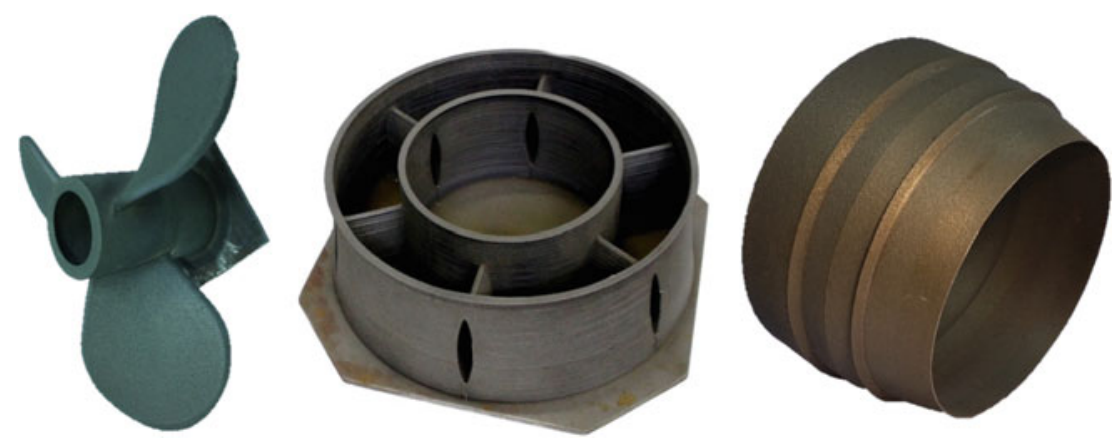

Fig. 4 Deposited samples 
different geometry without pores, cracks, poor fusion were obtained. The microstructure of the obtained products contains the fine grains with size less than 30 microns for nickel and iron alloys and 70 micron for titanium alloys (Fig. 5). Features of formation structure for the different alloys using this technology are given in the article the authors. [6, p. 980; 7, p. 718]. Fracture of HSDLD samples is characterized by ductile destruction in comparison with cast samples.

In comparing with cast samples, the products are manufactured by high-speed direct laser deposition technology and have ultrafine structure. It provides high level of mechanical characteristics (Fig. 6). For example, tensile strength of samples, which were produced from GS6U alloy by HSDLD, is higher $20 \%$ in comparison with cast samples, elongation of the material is increased to 3 times.

(a)

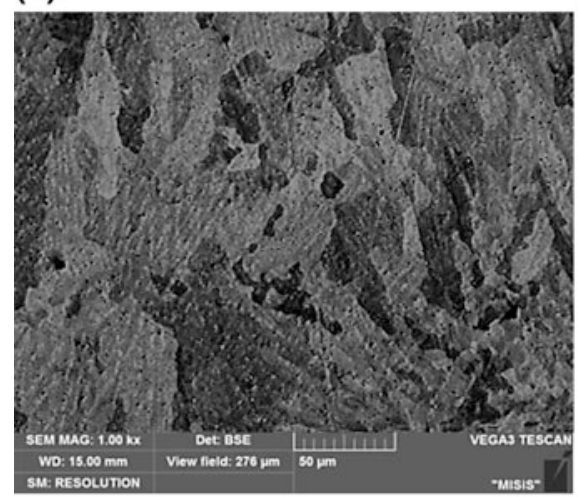

(c)

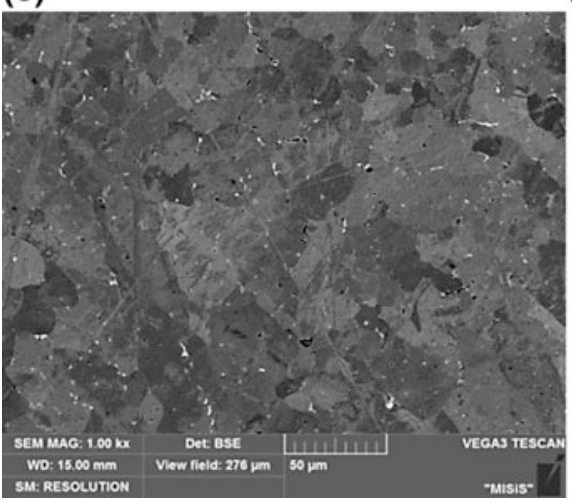

(b)

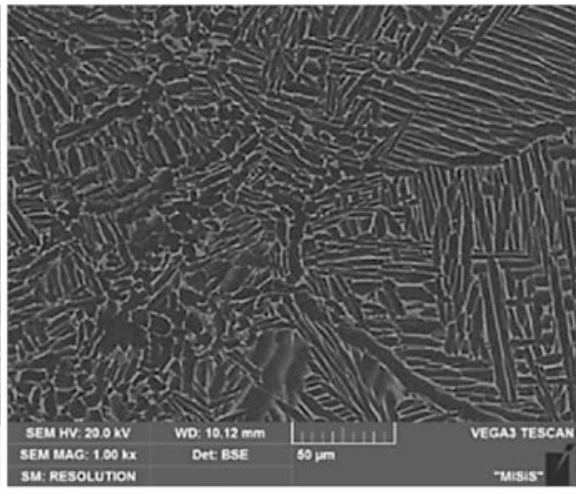

(d)

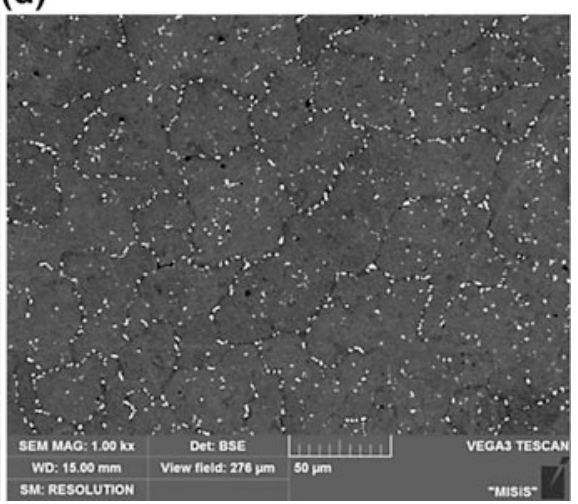

Fig. 5 Microstructure of deposited samples: a 316L steel, b titanium alloy VT20, c Inconel 625, d GS6U 

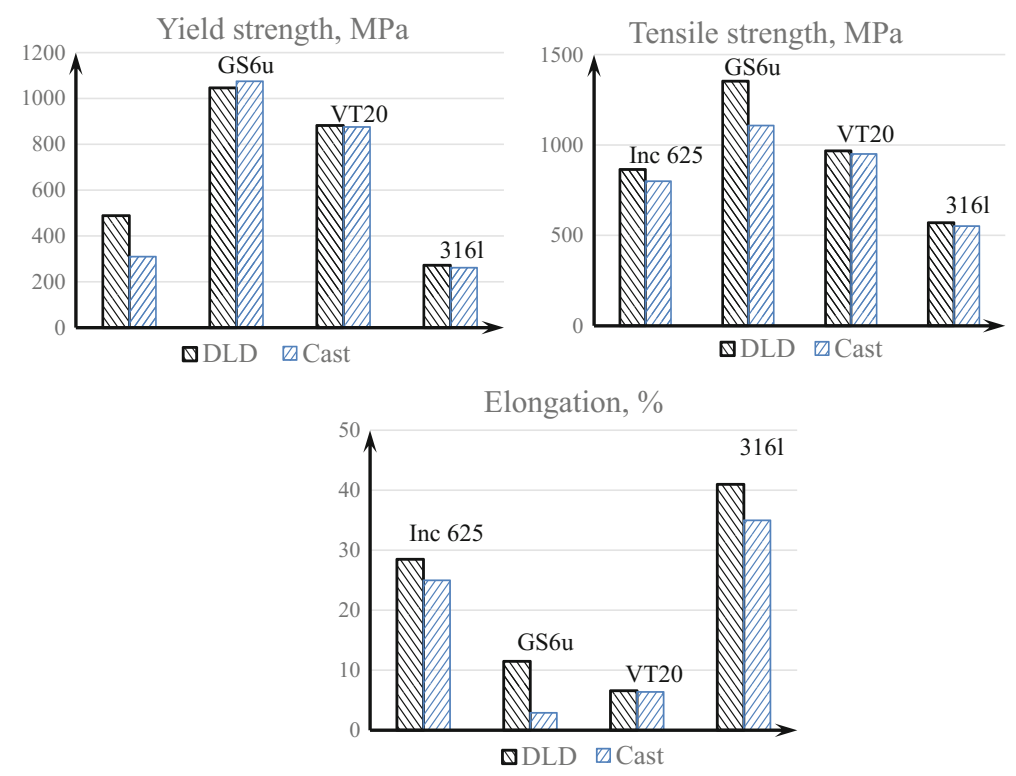

Fig. 6 Mechanical properties samples in deposited condition and cast condition

\section{Conclusions}

Direct laser deposition technology is a complex process with a large number of important parameters. The main requirements are stability of process formation of grown details and heterophase nature of the process. As a result, high-quality products with ultrafine structure could be achieved.

According the results of the project, first Russian equipment, which realize direct laser deposition technology, were manufactured. High-speed direct laser deposition is

- technology for manufacturing details with complex form from powder materials using 3D model;

- potential use different materials in a single part and obtaining details with gradient properties;

- dimensions of details are almost unlimited.

The process productivity is 10 times higher in comparison with layered synthesis technologies. Mechanical properties of the deposited parts at a level of hot rolled metal, there are no porosites, cracks.

Acknowledgements Project was done with the financial support of the Russian Ministry of education and science, FOP "Research and development on priority directions of scientific-technological complex of Russia for 2014-2020" Agreement (contract) no. 14.581.21.0010 December 01,2014 Unique project Identifier: RFMEFI5814X0010 


\section{References}

1. Adova, I.B., Azimov, Yu.I. et al.: Theoretical bases of formation of industrial policy. In: Babkin, A.V. (ed) FGAOU VO SPbPU. 462 p (2015)

2. Ageev, R.V., Kondratov, D.V., Maslov, Y.V.: Use of additive technology in the design and manufacture of parts for aerospace objects. Polet. Obscherossijsliy nauchno-technicheskiy J. 6, 35-39 (2013)

3. Dorochov, A.F., Abacharev, M.M., Additive technology in the production of shipboard power. Vestnik Astrachanskogo gosudarstvennogo technicheskogo universiteta, Seria: Morskaya technika I technologia. 2, 42-47 (2015)

4. Glukhov, V., Turichin, G., Klimova-Korsmik, O., Zemlyakov, E., Babkin, K.: Quality management of metal products prepared by high-speed direct laser deposition technology. Key Eng. Mater. 684, 461-467 (2016)

5. Kianiana, B., Tavassolib, S., Larsson, T.C.: The Role of Additive Manufacturing Technology in job creation: An exploratory case study of suppliers of Additive Manufacturing in Sweden. Procedia CIRP, 12th Global Conference on Sustainable Manufacturing. Emerging Potentials. 26, 93-98 (2015)

6. Klimova-Korsmik, O.G., Turichin, G.A., Zemlyakov, E.V., Babkin, K.D., Petrovskiy, P.V., Travyanov, A.Ya.: Structure formation in Ni superalloys during high-speed direct laser deposition. Mater. Sci. Forum. 879, 978-983

7. Klimova-Korsmik, O.G., Turichin, G.A., Zemlyakov, E.V., Babkin, K.D., Travyanov, A.Ya., Petrovskiy, P.V.: Structure formation in Ni superalloys during high-speed direct laser deposition. Phys. Procedia. 83, 716-722 (2016)

8. Olakanmi, E.O., Cochrane, R.F., Dalgarno, K.W.: A review on selective laser sintering/melting (SLS/SLM) of aluminum alloy powders: Processing, microstructure, and properties. Prog. Mater. Sci. 74, 401-477 (2015)

9. Seabra, M., Azevedo, J., Araújo, A., Reis, L., Pinto, E., Alves, N., Santos, R., Mortágua J.P.: Selective laser melting (SLM) and topology optimization for lighter aerospace components. Procedia Struct. Integrity. 1, 289-296 (2016)

10. Turichin, G.A., Klimova, O.G., Zemlyakov, E.V., Babkin, K.D., Kolodyazhnyy, D.Yu., Shamray, F.A., Travyanov, A.Ya., Petrovskiy, P.V.: Technological aspects of high speed direct laser deposition based on heterophase powder metallurgy. Phys. Procedia. 78, 397-406 (2015)

11. Turichin, G., Zemlyakov, E., Klimova, O., Babkin, K.: Hydrodynamic instability in high-speed direct laser deposition for additive manufacturing. Phys. Procedia. 83, 674-683 (2016)

12. Wilson, Michael J., Piya, C., Shin, Y.C., Zhao, F., Ramani, K.: Remanufacturing of turbine blades by laser direct deposition with its energy and environmental impact analysis. J. Clean. Prod. 80, 170-178 (2014) 
Open Access This chapter is licensed under the terms of the Creative Commons Attribution 4.0 International License (http://creativecommons.org/licenses/by/4.0/), which permits use, sharing, adaptation, distribution and reproduction in any medium or format, as long as you give appropriate credit to the original author(s) and the source, provide a link to the Creative Commons license and indicate if changes were made.

The images or other third party material in this chapter are included in the chapter's Creative Commons license, unless indicated otherwise in a credit line to the material. If material is not included in the chapter's Creative Commons license and your intended use is not permitted by statutory regulation or exceeds the permitted use, you will need to obtain permission directly from the copyright holder.

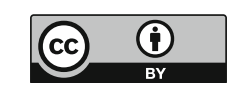

